\title{
Morpho-ecological structure of desert rodent communities in Central Asia and southwestern North America: a multivariate approach
}

\author{
K. A. ROGOVIN and A. V. SUROV
}

Rogovin K. A. and Surov A. V. 1990. Morpho-ecological structure of desert rodent communities in Central Asia and southwestern North America: a multivariate approach. Acta theriol. 35: $225-239$.

The principal components analysis and the cluster analysis were used to study the morpho-ecological organization of four desert rodent communities from Mongolia (Trans-Altai Gobi and Gobi-Altai) and Mexico (Central Chihuahua and Sonora). Twenty characters of external morphology of 41 species (representatives of 54 populations) were put into analysis. Results demonstrate a relatively low level of convergence between Mongolian and Mexican species. Rodent species of Mongolian communities occupy a bigger volume of the factorial space than rodent species of Mexican communities, although the number of species in both types of communities is similar. The comparison of Euclidean distances to the nearest neighbour and their coefficients of variation in real groups of coexisting species (at the level of habitat) and in hypothetical groups formed by random combination of species points to the pattern of regularity in species packing. At the same time there are differences in species distribution in morphological space of Mongolian and Mexican communities. The significant positive correlation of Euclidean distances in morphological and in ecological space (distances between centers of spatial niches) was shown in the community of Mongolian rodents. There is no such correlation in the Mexican rodent community. Predators and environmental conditions could be expected influencing community formation in deserts of Central Asia whereas in deserts of North America the role of interspecific competition is more probable.

Severtzov Institute of Animal Evolutionary Morphology and Ecology, Academy of Sciences of USSR, Leninskiy pr. 33, 117071 Moscow, USSR

Key words: community structure, desert rodens

\section{Introduction}

Interrelationships between ecological characteristics of animals and their morphological traits allow for a description of niches on the basis of morphology. These interrelationships are a common knowledge. The works by Kashkarov (1938) and Lack (1947) set first examples for using some external structures of animals as indicators of different niche parameters.

Since niche can be identified by morphological traits, it is possible to analize the dispersion of niches in a multivariate space, formed by morphological variation (Fenton 1972, Findley 1973, 1976, Gatz 1979, Karr and James 1975, Mares 1976, 1980, Ricklefs and Travis 1980, Ricklefs et al. 1981).

Although the morphological approach has its limitations in analyzing communities due to difficulties in selecting appropriate traits, it possesses a number of 
advantages compared to the traditional ecological approach (Ricklefs and Travis 1980). Morphological indicators may also be treated as an important supplement for ecological traits used in descriptions of spatial and trophic niches. For instance, morphological factors help to reflect adequately the distribution of centers of niches in ecological space.

The main issues that emerge in comparing the organization of communities by morphological factors can be formulated as follows: (1) How similar is the structure of assemblages occupying similar habitats? How are new species incorporated into communities (with or without increase of morphological hypervolume)? (2) What is the interrelationship between morphological relations of co-habitating species with trophic and habitat relations of these species? (3) Is there any difference in the distribution of species in real and random assemblages of species?

The answers to these questions suggest the possibility of identifying certain rules in the distribution of species. Questions about the causes of community structure cannot be addressed directly. We can only suggest mechanistic hypotheses that can be tested by other kind of approach.

Taking into account the above mentiond limitations, we used the morphological approach to compare the organization of four desert rodents communities, two from Mongolia (southern desert of Trans-Altai Gobi, and northern desert of Gobi-Altai), and the other two from the Chihuahuan (Bolson de Mapimi, Durango, Mexico) and Sonora (Pinakate, Sonora, Mexico) deserts of North America.

\section{Material and methods \\ Data collection}

We have analized 20 morphological traits of representatives of 54 populations of 41 species. All traits but one can be divided into two groups, those describing dimensions of structures, and those characterizing relations between dimensions of these structures (indices). Inclusion in the analysis of both dimensions of organs and their proportions (Mares 1976, 1980) is justified, because both are neccesary to describe fully the form of a given species. Differences in indices may point to different ways of using resources, divergence of species along different axes of ecological space. Differences in linear dimensions and body mass may provide evidence for the partitioning of species along some axes of ecological space. (For instance, differential use of different sizes of food items of the same type by consumers of different sizes).

We have used the following characters: (1) head and body length, (2) tail length, (3) hind fcot length (from the back of the heel to the tip of the longest toe nail), (4) ear length, (5) length of the longest vibrissae, (6) distance between eyes (frontal view), (7) length of the middle toe nail of front feet, (8) average length of hairs on the soles of hind feet (foot bristles), (9) height of the skin cushion (support callus) at the tip of the middle toe of the hind foot, (10) length of the tuft at the end of the tail, (11) number of toes used in locomotion, (12) body weight, (13) tail/head and body length ratio, (14) foot/head and body length ratio, (15) ear/head and body length ratio, (16) forelimb (from ulnaria)/hind foot length ratio, (17) distance between eyes/head and body length ratio, (18) front foot nail/hand length ratio, (19) longest vibrissae/head and body length ratio, (20) hind foot bristle length/height of support callus at the tip of the middle toe ritio.

The above mentioned characters were chosen in order to take into account peculiarities of the adaptations of species. Preference to these over other characters used in preliminary studies, was based on observations of animals in nature and on published information on the comparative and functional 
morphology of rodens (Gambaryan 1972, Fokin 1978). Characters from 1 to 12 describe body dimensions. Characters 2, 3, 5, and 10 are both related to dimensions of the body and to characteristic forms of locomotion. Characters and indices $11,13,14,16$, and 19 mostly reflect peculiarities of locomotion. Characters $4,7,15$, and 18 reflect the level of adaptation for burrowing and, in general, the ability to dig in the substrate (for instance in feeding). Characters 8, 9, 19, and 20 reflect adaptation to the type of substrate (loose or hard). Finally, characters 6 and 17 reflect the relationship of the species to the cover provided by vegetation. All measurements have been taken in the field either from the carcasses, or from alive animals (total of 836 specimens). Mean values of parameters were used in the analysis.

Each of the communities represented a set of populations of species, potentially interacting each other and occuring within a common set of habitats, which included a wide range both of substrates (from rocky slopes of mountains to clay and sand deserts in valleys) and of vegetation (from areas devoided of vegetation to thick covered of the oasis type in the deserts of Mongolia to areas of savannah interspersed in the deserts of Central Mexico).

Two communities of rodents, representing faunas of deserts in Mongolia and Mexico, were used for more detailed analysis toward of their spatial organization. The data of species distribution along the environmental gradient were collected in Trans-Altay Goby near Ehiin-Gol (Bayan-Hongor Aimak, Mongolia) in June-August of 1982 and 1983, and in the central part of the Chihuahua desert in Mapimi Biosphere Reserve near Ceballos (Durango, Mexico) in September-November of 1981 and 1983. The physiognomic similarity of habitat conditions was also the criterion (we analyzed the distribution of species from sand dunes to gently sloping mountain foothills, and to clay basins resulting from wind erosion and water accumulation). We have not observed any rare species. Their absence could be related in part to the particularities of the dynamics of their populations in the years of our studies. Records of rodents were obtained by trapping with Sherman traps $(25 \times 7 \times 7 \mathrm{~cm}$ in size) in square 1-ha grids ( 22 in Mongolia and 20 in Mexico). Each of these grids was subdivided into 25 sample plots of 20 by $20 \mathrm{~m}$. The centers of sample plots were marked with pegs. Two traps were set in less then $5 \mathrm{~m}$ distance from the center of each sample plot one in the open, and the other close to a shrub (shelter). Rodents were marked by toe-clipping and by dyeing fur with "Urzol-D" and released. Traps were examined three times each night. Jerboas, kangaroo rats and pocket mice not trapped in Sherman traps were caught with a net at night. Only points of the first capture were used in the following analysis. Each grid was checked over a period of three nights. Distribution of rodent species on each grid were estimated by the number of plots with animals caught during this time. The environment was described in the center of each sample plot by 32 characters including soil structure, vegetation and relief. (Detailed description see in Rogovin et al. 1991).

\section{Statistical approach}

We studied the distribution of species in the morphological space using principal components analysis (PCA). The mathematics of PCA is based on parametric statistics and assumes normality of the analyzed parameters. It is evident that the demand for the normality is violated by using mean values of characters in interspecies comparisons. The same happens in using size ratios. As noted by Jeffers (1981), this excludes the possibility of precise statistical evaluation of results. Providing the distribution of morphological factors is limited by the range of positive values of the numerical axis (the function is fully determined in that area), however, the structure of finite model turns out to be relatively insensitive to deviation from normality. We did not include in PCA character 11 because in a series of species its change takes place with rather big increments which does not give us the grounds to view it as a continuous parameter.

Besides the PCA we have also estimated the Euclidian distances between all pairs of species by 20 morphological traits:

$$
D_{i j}=\left[\sum_{k=1}^{20}\left(x_{i k}-x_{j k}\right)^{2}\right]^{\frac{1}{2}}
$$

where $D_{i j}$ is the Euclidian distance between species $i$ and $j ; X_{i k}$ and $X_{j k}$ - mean values of $k$ - character in $i-$ and $\mathrm{j}$-species. Mean values of each of these traits have been preliminary standardized: 


$$
\mathrm{x}^{\prime}=\frac{\mathrm{x}-\overline{\mathrm{x}}}{\sigma_{\mathrm{x}}}
$$

were $\mathrm{x}^{\prime}$ is the standardized value of the character; $\mathrm{x}$ is the mean value of the character for each species, $\overline{\mathrm{x}}$ is the mean for all species in the community, $\sigma_{\mathrm{x}}$ is the standard deviation.

The matrix of Euclidean distances was used to classify 41 species by the entire set of characters. Classification was performed on the basis of iterative procedure of clusterization (Skulkin 1978). The algorithm of the process is based on a series of correlations of lines of the initial matrix till obtaining such state when the matrix proves to be divided into two subsets with meanings $r=+1$ and $r=-1$. Each iteration means correlation of each line of the matrix with all other lines. All characteristics which have coefficients of +1 in the limit are referred to one subset, all other characteristics with coefficients of -1 to another one. Then the procedure have to be repeated again within each subset of the initial matrix till obtaining the new level of subdivision. In such a way we obtain the dichotomic procedure of classification provided with a consecutive division of the whole set into pairs of subsets, from general to particular.

At first approximation differences in the organization of communities were identified by comparing regression curves of the Euclidean distances (Inger and Colwell 1977). To plot them, the distances from each species to all others in the community were ranged from the maximal to the minimal distance by the nearest-neighbour principle. Then a mean value of the distance and coefficient of variation were derived for each rank. Rank number can be viewed as a level of morphological closeness. The shape of the curve can be interpreted as describing the level of evenness in species packing in the morfological space.

We have studied morphological relationships of species in real groups that cooccur in 1-ha grid areas in different habitats. In every group we identified distances for all species from the nearest neighbour in the group, mean value and coefficient of variation. The distance to the nearest neighbour should be the most regular characteristic, and it should be relatively insensitive to a change in the number of species (Ricklefs and Travis 1980). The real communities were compared with randomly organized ones ( 0 -hypothesis). To formulate 0 -hypothesis, out of the species that actually populate the area and which may potentially interact with each other, randomly organized groups were formed whose number corresponded to the actual number of species inhabiting 1-ha plots within the boundaries of the community habitat (Ricklefs and Travis 1980, Ricklefs et al. 1981). Twenty random groups were formed for each case of $2,3 \ldots \mathrm{n}$ species. Each of the species could be included into a random group only once. For such groups we determined mean Euclidean distances to the nearest neighbour and coefficients of variation in real groups with a different number of species from such in groups, organized randomly.

Table 1. Eigenvalues and eigenvectors of the first three principal components ( $\mathrm{PC1}, \mathrm{PC} 2, \mathrm{PC} 3)$ calculated by the correlation matrix of 19 morphological characteristics of species. ${ }^{*}$ numbers of eigenvalues are the same as numbers of the characters, see in "Material and methods".

\begin{tabular}{|c|c|c|c|c|c|c|c|c|c|}
\hline \multirow[b]{2}{*}{$\begin{array}{l}\text { Principal } \\
\text { component }\end{array}$} & \multirow[b]{2}{*}{$\begin{array}{l}\text { Eigen- } \\
\text { value }\end{array}$} & \multirow[b]{2}{*}{$\begin{array}{l}\text { Cumulative } \\
\text { per cent }\end{array}$} & \multicolumn{7}{|c|}{ Eigenvector values $(\mathrm{PC} 1, \mathrm{PC} 2, \mathrm{PC} 3)$} \\
\hline & & & $\begin{array}{c}1 \\
8 \\
16\end{array}$ & $\begin{array}{c}2 \\
9 \\
17\end{array}$ & $\begin{array}{c}3 \\
10 \\
18\end{array}$ & $\begin{array}{c}4 \\
12 \\
19\end{array}$ & $\begin{array}{c}5 \\
13 \\
20^{\circ}\end{array}$ & $\begin{array}{c}6 \\
14\end{array}$ & $\begin{array}{c}7 \\
15\end{array}$ \\
\hline \multirow[t]{3}{*}{1} & 8.54 & 44.95 & 0.07 & 0.30 & 0.31 & 0.15 & 0.30 & 0.25 & 0.21 \\
\hline & & & 0.27 & 0.22 & 0.23 & 0.09 & 0.23 & 0.29 & 0.11 \\
\hline & & & -0.29 & 0.18 & 0.24 & 0.23 & 0.08 & & \\
\hline \multirow[t]{3}{*}{2} & 4.08 & 66.45 & 0.46 & 0.07 & 0.16 & 0.17 & 0.09 & 0.27 & 0.10 \\
\hline & & & -0.08 & 0.26 & 0.06 & 0.42 & -0.28 & -0.21 & -0.06 \\
\hline & & & 0.15 & -0.13 & -0.20 & -0.31 & 0.08 & & \\
\hline \multirow[t]{3}{*}{3} & 2.45 & 79.38 & 0.06 & -0.05 & -0.05 & -0.50 & -0.18 & 0.16 & 0.34 \\
\hline & & & 0.04 & -0.11 & 0.32 & 0.05 & -0.03 & -0.08 & -0.56 \\
\hline & & & -0.03 & 0.17 & 0.25 & -0.14 & 0.09 & & \\
\hline
\end{tabular}


We also studied patterns of spatial structure of two types of communities using principles of information-logical analysis (Puzachenko and Skulkin 1981). Factors of environment influencing the distribution of species in nature were selected by the scheme proposed earlier (Rogovin and Skulkin 1976). At the first stage only factors with significant information coefficients of conjugation with the species where selected (evaluation of significance by $\chi^{2}$ ). At the second stage independent environmental factors were selected from this group in the course of procedure of cluster analysis described above. Ecological optima for each species were determined using conditional probabilities of species occurrence along the gradient of each of independently acting and significantly influencing factors. Distances between centres of spatial niches of coexisting species were derived by calculating Euclidean distances between such ecological optima for factors selected.

\section{Results and discussion}

The results of the PCA reveal that the first three components account for $79 \%$ of the total variance of morphological traits. The first PC makes about $45 \%$ of variance, the second about $21 \%$, and the third $13 \%$. In this way we may consider that the space of factors, formed by the axes of the first three PC, is sufficient to characterize the distribution of the analyzed set of rodent species. The values of eigenvectors enable us to determine the most informative combinations of traits.

The first PC mainly reflects the opposition of character 16 to characters $2,3,5,14$, and 8. The distribution of species along the axis of this PC (Fig.1) is related to their shape, i.e. with the proportions of the body parts that are used in different types of locomotion and the level of adaptation to open areas of desert. The jerboas most specialized in bipedal locomotion followed by less specialized bipedal forms (pygmy jerboas Cardiocraniinae and kangaroo rats Dipodomys), then by species using a primitive ricocheting gallop (gerbils Gerbilinae and pocket mice Perognathus), galloping ground squirrels (Spermophilus, Ammospermophilus) and, finally, the species, using mainly symmetric gaits (hamsters Cricetinae, yellow steppe lemming Eolagurus, mountain voles Alticola, mouse Mus). The second component reflects mainly of linear dimensions and body mass (characters 1 and 12). Along the axes of this PC the species of rodents are distributed mainly in line with overal body size (Fig. 1 A). And finally, the third component reflects mainly positive relationship of characters 15 and 4, and also opposition of their influence to characters 7, 10 and 18 . This PC is not interpreted as easily as the first two. From a certain point of view it can be characterized as the component that reveals the relationship between species of rodents with burrows or other surface shelters like nests, thick bushes, etc.

The analysis of rodent species distribution in the space of the first and second PC, and also of the first and third PC, providing the highest variance among species, enables to identify the following features (Fig. 1 A, B).

1. Rodent communities of the southern and northern deserts of Mongolia occupy larger volume of the factorial space than rodent communities in the deserts of central northwestern Mexico. This points to a greater morphological and ecological variability in rodents from central Asian deserts. 
2. Convergent development of ecological forms of rodents in deserts of northern America and central Asia involves not the whole set of characters included in the analysis, but only some groups of them. For instance, the size of the body and extremities turn out to be linearly independent parameters. In North America and Central Asia similarly shaped forms have different body sizes (for instance, Asian gerbils and American pocket mice).

Projection of species on the first and third axes forms groups that correspond to the traditional concept of life forms of rodents as of groups of species populating one landscape-climatic zone. Pocket mice and gerbils, and, to lesser extent, kangaroo rats and some jerboas may be viewed as convergent forms in this system of coordinates.

3. Introduction or substitution of species in spatially separated Mexican communities takes place virtually without changing the volume of the factorial space occupied by the community. On the other hand, in Mongolia, changes in the structure of communities occur due both to the infiltration of species into the already occupied area of the factorial space, and also to the expansion of the space around the periphery of the community (location of long-eared jerboa Euchoreutes naso). Nevertheless, the areas of factorial space occupied by species of communities of one continental fauna
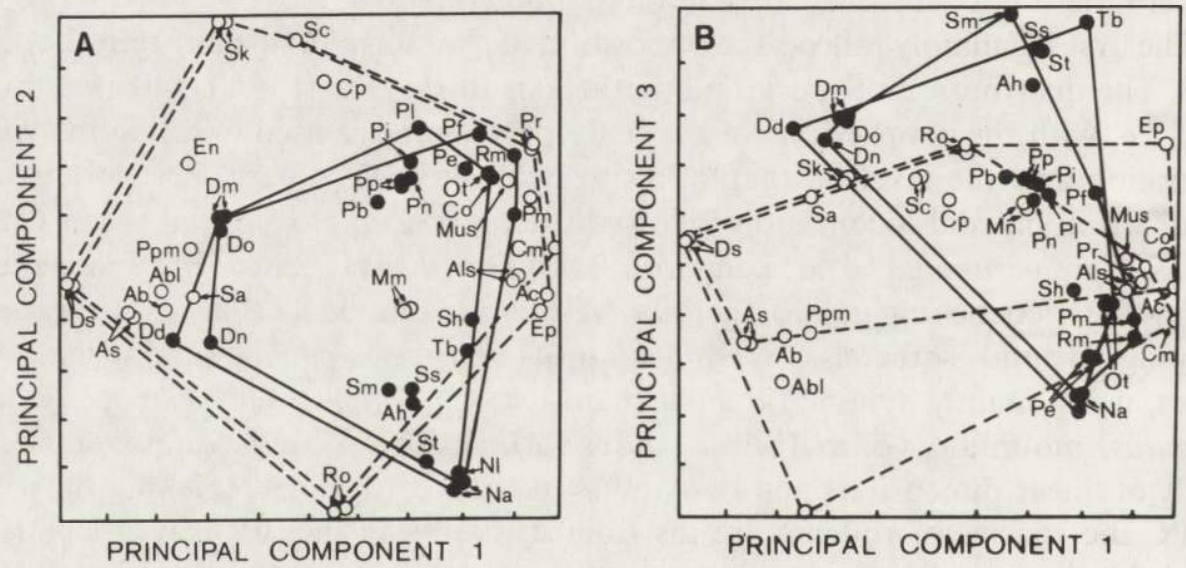

Fig. 1. Position of rodent species in the coordinate system of (a) first and second, and (b) first and third principal components, describing morphological space of communities. Dashed line and white circles designate Mongolian communities, solid line and blackcircles - Mexican communities.

Species of rodents: Sc - Salpingothus crassicauda, Sk - S. kozlovi, Cp - Cardiocranius paradoxus, En - Euchoreutes naso, As - Allactaga sibirica, Abl-A. balicunica, Ab-A. bullata, $\mathrm{Ppm}$ - Pygerethmus pumilio, Ds - Dipus sagitta, Sa - Stylodipus andrewsi, Ro - Rhombomys opimus, $\mathrm{Mm}$ - Meriones meridianus, $\mathrm{Cm}$ - Cricetulus migratorius, $\mathrm{Co}-$ C. obscurus, Ac - Alocricetulus curtatus, $\mathrm{Pr}$ - Phodopus roborovskii, Als - Alticola stoliczkanus, Ep - Eolagurus przewalskii, Mus - Mus musculus, Sm - Spermophilus mexicanus, Ss - S. spilosoma, $\mathrm{St}-\mathrm{S}$. tereticaudus, $\mathrm{Ah}$-Ammospermophilus harrisi, $\mathrm{Tb}$ - Thomomys botae, $\mathrm{Pf}-$ Perognathus flavus, $\mathrm{Pl}-\mathrm{P}$. longimembris, $\mathrm{Pb}-\mathrm{P}$. baileyi, $\mathrm{Pp}-P$. penicillatus, $\mathrm{Pi}-P$. intermedius, $\mathrm{Pn}-P$. nelsoni, $\mathrm{Dm}$ - Dipodomys merriami, Do - D. ordii, Dn - D. nelsoni, Dd - D. deserti, Rm-Reithrodontomys megalotis, Ot - Onychomys torridus, $\mathrm{Sh}$ - Sigmodon hispidus, $\mathrm{Na}$ - Neotoma albigula, $\mathrm{Nl}-\mathrm{N}$. lepida, $\mathrm{Pe}-$ Peromyscus eremicus, $\mathrm{Pm}-P$. maniculatus. 
generally coincide. However, there is only partial coincidence of the morphological space of rodents from central Asian and North American deserts (Fig. 1 A, B). The level of morphological similarity is limited. This furnishes the evidence of the influence of more than any one factor in the evolution of North American and central Asian desert rodents.

In line with the conclusions derived from the PCA, all species of rodents were also compared by the Euclidean distance measure in the space of 20 morphological traits (Fig. 2). These results suggest a low level of convergence of rodents in Mongolian and Mexican deserts. The groups which species form at the low and medium levels in a dendrogram are mainly represented by taxonomically close forms, from one of the two continents. Exceptions are two pairs of species, one containing Andrew's

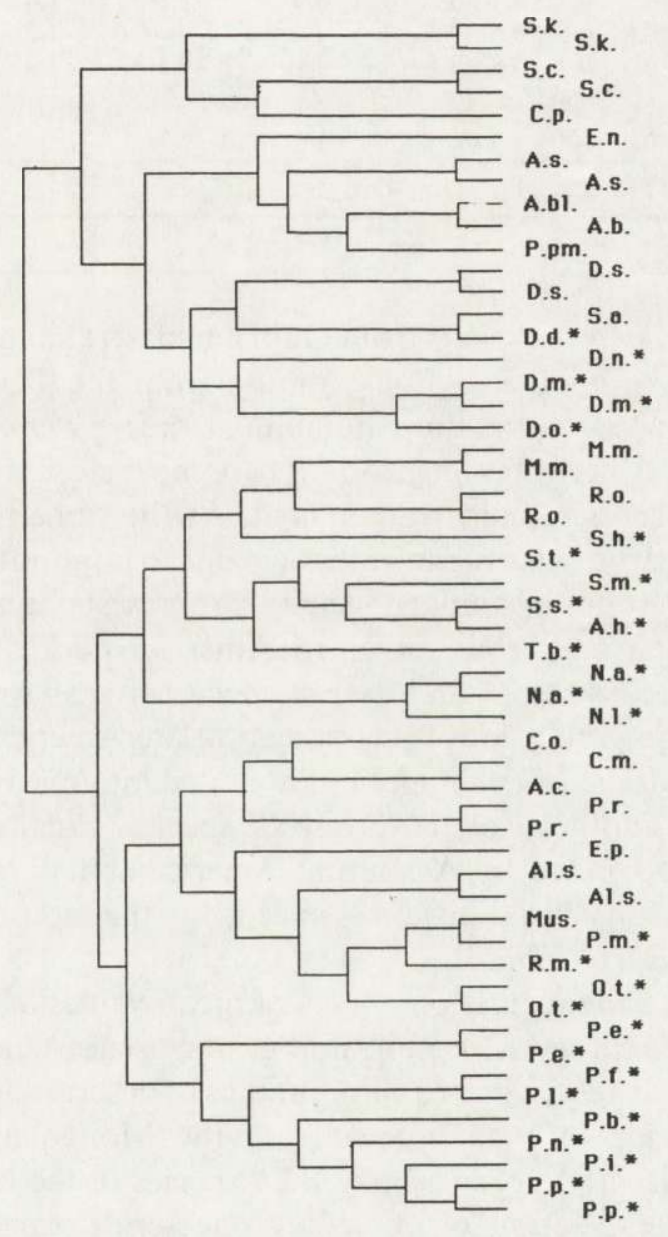

Pig.2.

Fig. 2. Morphological classification of desert rodents - results of the cluster analysis of Euclidean distances between species in the space of 20 morphological characters. Mexican species are designated by asteriks. 
Table 2. Euclidian distances between species in the morphological space of Mongolian (Trans-Altai Gobi) community (above the diagonal) and of Mexican (Mapimi) community (below the diagonal).

\begin{tabular}{|c|c|c|c|c|c|c|c|c|c|c|c|c|c|c|}
\hline \multicolumn{15}{|c|}{ Trans - Altai Gobi (Mongolia) } \\
\hline & $\mathrm{Sk}$ & $\mathrm{Sc}$ & $\mathrm{Cp}$ & En & As & $\mathrm{Abl}$ & Ds & $\mathrm{Mm}$ & Ro & $\mathrm{Cm}$ & $\operatorname{Pr}$ & Als & Mus & \\
\hline S. mexicanus & - & 0.5 & 0.8 & 1.3 & 1.5 & 1.4 & 1.3 & 1.5 & 1.8 & 2.0 & 1,7 & 2.0 & 1.7 & S. kozlovi \\
\hline S. spilosoma & 0.2 & - & 0.5 & 1.3 & 1.5 & 1.4 & 1.5 & 1.3 & 1.6 & 1.7 & 1.4 & 1.7 & 1.3 & S. crassicauda \\
\hline$P$. flavus & 1.2 & 1.2 & - & 1.3 & 1.5 & 1.3 & 1.4 & 1.1 & 1.5 & 1.5 & 1.3 & 1.6 & 1.1 & C. paradoxus \\
\hline P. nelsoni & 1.1 & 1.0 & 0.5 & - & 0.9 & 0.9 & 1.3 & 1.6 & 1.8 & 2.0 & 2.0 & 1.9 & 1.7 & E. naso \\
\hline$P$. penicillatus & 1.0 & 1.0 & 0.5 & 0.1 & - & 0.4 & 0.9 & 1.5 & 1.5 & 2.2 & 2.2 & 2.0 & 1.7 & A. sibirica \\
\hline D. merriami & 1.1 & 1.2 & 1.3 & 1.1 & 1.0 & - & 0.8 & 1.4 & 1.4 & 2.0 & 2.0 & 1.8 & 1.8 & A. balicunica \\
\hline D. nelsoni & 1.1 & 1.1 & 1.6 & 1.3 & 1.2 & 0.5 & - & 0.8 & 1.5 & 2.3 & 2.2 & 2.2 & 2.1 & D. sagitta \\
\hline N. albigula & 1.3 & 1.1 & 1.4 & 1.2 & 1.3 & 1.7 & 1.5 & - & 0.8 & 1.0 & 1.1 & 1.0 & 0.7 & M. meridianus \\
\hline O. torridus & 1.3 & 1.1 & 0.5 & 0.7 & 0.7 & 1.5 & 1.0 & 1.1 & - & 1.5 & 1.6 & 1.4 & 1.5 & R. opimus \\
\hline P. eremicus & 1.4 & 1.3 & 0.6 & 0.6 & 0.6 & 1.4 & 1.6 & 1.1 & 0.4 & - & 0.7 & 1.2 & 0.8 & C. migratorius \\
\hline \multirow[t]{3}{*}{ P. maniculatus } & 1.3 & 1.1 & 0.6 & 0.7 & 0.8 & 1.6 & 1.7 & 1.0 & 0.3 & 0.4 & - & 1.3 & 0.9 & P. roborovskii \\
\hline & & & & & & & & & & & & & 1.0 & A. stoliczkanus \\
\hline & $\mathrm{Sm}$ & $\mathrm{s}$ & $P$ & $\mathrm{Pn}$ & $\mathrm{Pn}$ & & I & $\mathrm{N}$ & Ot & $\mathrm{P}$ & & & & \\
\hline & & & & & & $\mathrm{Ma}$ & $n 1$ & 10 & & & & & & \\
\hline
\end{tabular}

three-toed jerboa Stylodipus andrewsii from Gobi and desert kangaroo rat Dipodomys deserti from Sonora, the another - house mouse from the Trans-Altai Gobi Mus musculus and a deer mouse from the Chihuahuan desert Peromyscus maniculatus. Among bipedal forms, American kangaroo rats are most close to three-toed jerboas, also the level of differences remains rather high. At the same time pygmy jerboas, similar in shape to kangaroo rats are far from them due to large differences in sizes. The same desintegration of groups of similarly shaped forms can be seen during the analysis of quadrupedal species (Asian gerbils and North American pocket mice, and also north American woodrats Neotoma spp. and deer mice Peromyscus spp.

Most close to Asian gerbils in this classification are American ground squirrels. Together with the woodrats, all these species are united into one big group. American pocket mice represent another isolated group of species. Finally, another group of quadrupedal rodents is formed by Asian and American small hamster-like species; these are separated by substantial distances except for the mouse Mus musculus and deer mouse Peromyscus maniculatus.

The relationships of the regression curves of mean values of Euclidian distances between species of different levels of morphological closeness and the coefficients of variation $(\mathrm{CV})$ of these distances in two communities of desert rodents from Mongolia and Mexico are reflected in Fig. 3. Species in the Mongolian community were consistently and significantly more variable than species in the Mexican community (here and below by the criterion of exceeding one series over another, $p<0.001$; Plokhinsky 1970). This tallies with the results of the PCA. At the same time, the CV value of distances between the nearest neighbours is substantially large in the community of Mexican desert rodents. The difference in the $\mathrm{CV}$ values per se points to 


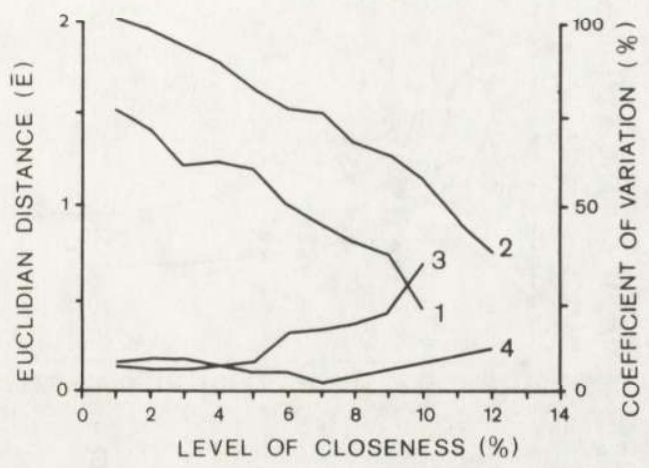

Fig. 3. Dependence of the average value of Euclidean distances between species (E) and coefficients of variation $(\mathrm{CV}, \%)$ of these distances on the level of the morphological closeness of species (the latter increases along the abscissa axis from left to right). 1 - mean $\mathrm{E}$ values for the Mapimi community (Mexico), 2 - mean E values for the Trans-Altai Gobi community (Mongolia), 3-CV in the Mapimi community, $4-\mathrm{CV}$ in the Trans-Altai Gobi community.

the differences in the organization of communities. A lower value of the $\mathrm{CV}$ in Mongolia in combination with a larger value of the Euclidian distances may show a more dense packing of the Mongolian species in the morphological space. On the other hand, these features may reflect a different level of the taxonomic relatedness among species of each fauna, and may be only indirectly related to the ways that species have partitioned the ecological space.

The communities that we have analyzed are formed of species that use the whole spectrum of habitats in the region. At the same time the character of species packing in groups of locally coexisting species may be essentially different than the pattern for the fauna of a larger region. Species that use similar food resources (as a rule phylogenetically, and therefore, morphologically close species) may often be divergent in their use of habitats (Schoener 1974).

Our analysis of the morphological organization of species assemblages, populating particular habitats along similar geomorphological gradients within the Mongolian and Mexican deserts, supports the above mentioned considerations and enables us to represent more objectively the peculiarities of the combination of species.

Fig. 4 (A and B) depicts average distances to the nearest neighbour and CV in groups from 2 to 8 species, that were found together in various habitats in Mongolia and Mexico. These values are compared with similar characteristics, obtained for similar-sized groups formed by a random draw out of the pool of species in the community of each type.

Average distances to the nearest neighbour in groups, formed by a random combination of species of Mongolian rodents significantly surpass comparable random drows from Mexican communities $(p<0.001)$ which, quite naturally, is related to the greater interspecies variation in Mongolian community (Fig. 4 A, see also Fig. 3). 

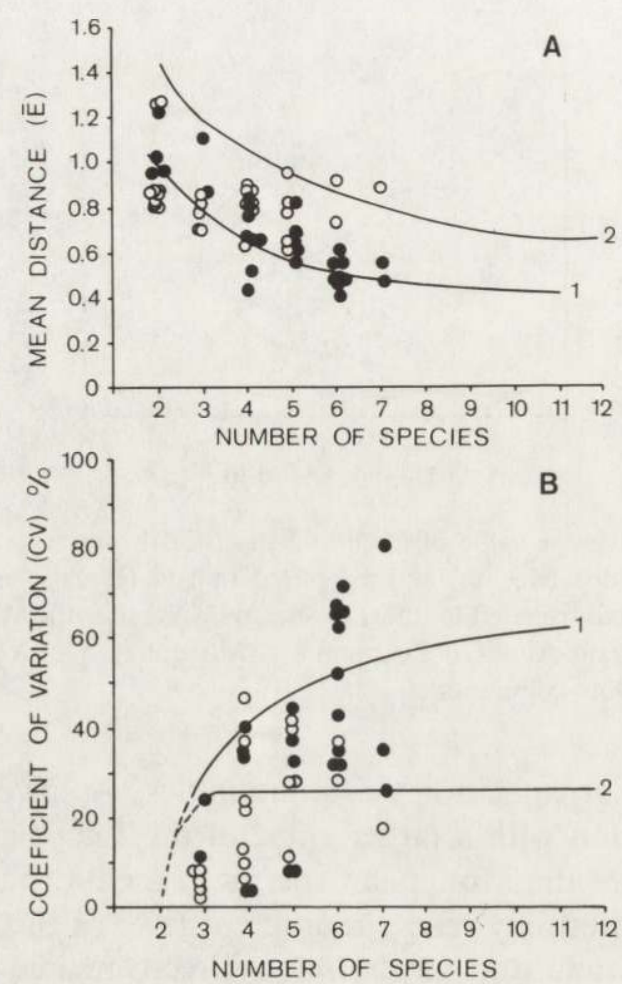

Fig. 4. Dependence of the mean distance to the nearest neighbour (A) and of coefficients of variation of distances (B) on the number of species in the biotopic group. Line means level of the process for the random groups: (1) in the Mapimi community, (2) in the Trans-Altai Gobi community. Black circles - real biotopic groups in Mapimi community. White circles - the same in Trans-Altai Gobi community.

However, at the level of groups consisted of locally coexisting species, each of the communities has similar distribution of values to a great extent for assamblages of $4-5$ species. In the groups with a smaller number of species ( $2-3$ species) inhabited simply structured habitates average distances to the nearest neighbour are usually larger in Mexico. On the contrary, for groups formed of 6 and more species, average distances to the nearest neighbour in Mexico are less than in Mongolia. The latter may reflect structural complexity of the environment in Mexican desert. The plots on which six or more species occurred were located in complexly structured ecotonal habitats, and, as a consequence, they contained morphologically similar species (representatives of the different habitat types) as well as morphologically distant species.

$\mathrm{CV}$ of distances to the nearest neighbour in randomly organized groups increase with an increase of the number of species in a Mexican community, whereas in a Mongolian community they remain virtually unchanged (Fig. 4 B). This also tallies with Fig. 3. For real groups of species from local sites of Mongolian and Mexican desert within the Mexican community CVs are higher at the initial and final section of 
the axis of the number of species. The first may reflect more regular packing of Mongolian species in small sized assemblages from simply structured habitats. At the same time there is a substantial overlap of areas of the distribution of points in the graph. A substantial increase of $\mathrm{CV}$ in the real groups consisted of a large number of species in Mexico again may reflect the result of including complex structured boundary habitats with morphologically close and distant species.

In respect to the groups that were formed at random, average distances to the nearest neighbour are less in Mongolian real assemblages $(p<0.001)$. At the same time in a Mexican community the differences are not significant, although there is a slight tendency of the oposite action to the first case. $\mathrm{CV}$ of distances to the nearest neighbour in real groups, formed by a small number of species in both types of communities, are located below the lines characterizing randomly organized groups. It points to the tendency toward the regularity of species packing in small sized assemblages. (The significance of differences has not been estimated due to a small number of groups with a small number of species). Although with an increase of the number of species in real groups the difference from the groups, formed at random gradually disappears, in a Mexican community the tendency towards regular combination of species is more pronounced.

In this way the approach towards the analysis of the morphological organization in the communities of Mongolian and Mexican desert rodents shows substantial differences in their organization. These differences are determined both by a low level of convergence of morphological forms of rodents on both continents and by a different level of interspecies morpho-ecological variation of rodents within each type of the community. Taxonomic distances between species in the communities of Mongolian and Mexican deserts are essentially different. Mongolian communities are as a rule formed by the representatives of different genera and even subfamilies of rodents whereas in Mexican communities species of one genus often occur together. Apparently the level of morpho-ecological differences between species within communities is directly related to the peculiarities of their taxonomic organization.

Phylogenesis of the principal taxa, determining the composition of communities of both types probably ran parallel. Early finding of fossil ricocheting rodents are referred to the Miocene. Jerboas similar to contemporary forms have been found in early Miocene deposits in Central Asia. Jerbils appear in central Asia at the end of the Miocene (Shevyreva 1983). Divergence of heteromyid rodents was well under way in North America in the Miocene-Pliocene (Lidsay 1972, Hafner 1978, Patton et al. 1981, Hafner and Hafner 1983). The initial isolation and differentiation of the family of Heteromyidae as well as of the family of Dipodidae began back in the Oligocene (Wood 1935, Shevyreva 1983).

The formation deserts in North America and Asia took place almost at the same time due to the processes of mountain formation in the Miocene-Pliocene (Axelrod 1950, Sinitzin 1967, Petrov 1973, Bailey et al. 1977). However, the rate of development of desert landscapes on each continent remained different. In the Neogene North 

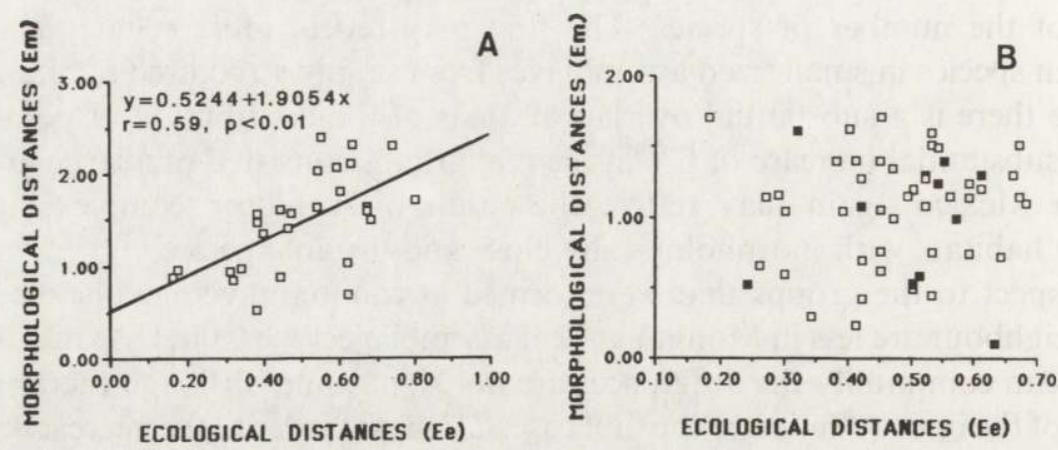

Fig. 5. Dependence of Euclidian distances between species in the space of morphological factors (Em) on the distances between centres of their spatial niches (Ee). A - community of Mapimi (Mexico), B - community of Trans-Altai Gobi (Mongolia). Black circles - species of heteromyid rodents.

American deserts did not reach the same level of development as in Asia. The formation of desert vegetation was restricted to small sections of low mountains, whereas valleys were occupied by forests for a long time (Axelrod 1975, 1979). In Pleistocene glacial periods the Sonoran desert (one of the most arid ones at present in North America) was represented by mosaics of xeric refugees, intermingled with mesic habitats (Martin and Mehringer 1965). Similar conditions existed in post-glacial period in the Mohave, Sonoran and Chihuahuan deserts. Rapid dessication of landscapes in these modern deserts began simultaneously about 8,000 years ago (Van Devender 1977, Van Devender and Spaulding 1979, Van Devender and Burgess 1985). The mosaic nature of the distribution of arid landscapes in North America could promote an increase of the rate of species formation, was not reflected in the morphological and ecological divergence of forms of desert rodents. At the same time there is every ground to consider that the dessication of Asia, including Central Asia, took place on a larger scale than in North America (Petrov 1973, Babaev et al. 1986). The present Mongolian deserts stand out in their extremely low productivity. Diversity of plant species, unlike in Mexican deserts, is extremely low, and the structure of plant communities is more simple. Although similar in topographic relief and the structures of the substrate and vegetation in deserts on both continents, the histories and patterns of these habitats are indisputably different.

Thus the existing differenes in the morphological and ecological adaptation of species in Mongolian and Mexican communities can be explained by the history of habitat conditions. Differences of these conditions in large regions with arid climates could influence the rate of ecological and morphological divergence of desert rodents. It should be also noted that communities of southern and northern deserts of Mongolia do not include such species of rodents as suslics Citellus and mole-voles Elobius ecologically and morphologically equivalent to American ground squirrels Spermophilus and gophers Geomyidae. The above mentioned Asian forms do not 
penetrate at present into the desert area due to high aridity of the climate, but inhabited this area in past. The introduction such species as Citellus palidicauda and Ellobius tancrei into the analysis would even further encrease the volume of the morphological space of Mongolian communities.

Our analysis has also revealed differences between the organization of real locally coexisting sets of species and groups drawn at random and points to the regularity in community structures. However such a regularity can be identified only in the groups of locally coexisting species. The differences in the organization of groups, identified by morphological factors, point to the difference in the ecological organization of these groups in communities of each type. The evidence of this is the difference in the correlation of distances between the centres of spatial niches of species with distances between species in the space of morphological factors in communities of Mongolia and Mexico (Fig. 5). Significant positive correlation $(r=0.56, p<0.01)$ between these characteristics in Mongolia (Fig. 5A) speaks in favour of the priority effect of environmental conditions, since similar morphological species have a tendency to live in similar environments. This result can also be explained by the impact of predations, which could be also viewed as an external condition with respect to the community. Whereas the absence of the significant correlation between the above mentioned characteristics in Mexico $(r=-0.14)$ can be inferred by the influence on the community organization of such a factor as interspecific competition (Fig. 5B). In reality competition in communities of American desert rodents has been confirmed experimentally (Munger and Brown 1981, Lemen and Freeman 1983, 1987; etc.).

Acknowledgements: This work was done as a part of a joint programme for research in ecology between Instututo de Ecologia (Mexico) and Institute of Animal Evolutionary Morphology and Ecology of the USSR Academy of Sciences (Moscow) and was supported by Consejo Nacional de Siencia y Tecnologia of Mexico and Academy of Sciences of the USSR. We wish to thank Dr. G. Halffter, Dr. P. Reyes-Castillo, Dr. M.-E. Maury and Dr. V. Serrano for their aid on this project. We also thank Dr. J. Brown of the University of New Mexico for his comments on the draft of this paper.

\section{References}

Axelrod D. I. 1950. Evolution of desert vegetation in Western North America. Carnegie Inst. Publ. 590: 217-306.

Axelrod D. I. 1975. Evolution and biogeography of Madrean-Tethyan sclerophyll vegetation. Ann. Missouri Bot. Gard. 62: $280-334$.

Axelrod D. I. 1979. Age and origin of the Sonoran desert vegetation. Occas. Papers of the Calif. Acad. Sci. 132: $1-74$.

Babaev A. G., Zonn I. S., Drozdov N. N. and Freikin Z. G. 1986. [Deserts.] Mysl, Moskva: 1-319. [In Russian]

Bailey H. P., Simpson B. B. and Vervoorst F. 1977. The physical environment: the independent variable. [In: Convergent evolution in warm deserts. G. H. Orians and O. T. Solbrig, eds]. Hutchinson and Ross Publ., East Stroudsburg, Pensylvania, Dowden: $13-49$.

Gambarian P. P. 1972. [Run of Mammals.] Nauka, Leningrad: 1-334. [In Russian]

Fenton M. B. 1972. The structure of aerial-feeding bat faunas as indicated by ears and wing elements. Can. J. Zool. 50: 287-296. 
Findley J. S. 1973. Phenetic packing as a measure of faunal diversity. Amer. Natur. 107: 580-584.

Findley J. S. 1976. The structure of bat communities. Amer. Natur. 110: 129-139.

Fokin I. M. 1978. [Locomotion and morphology of locomotor system of jerboas.] Nauka, Leningrad: 1-118. [In Russian]

Gatz A. J. 1979. Community organization in fishes as indicated by morphological features. Ecology 60 : $711-718$.

Hafner J. C. 1978. Evolutionary relationships of kangaroo mice, genus Microdipodops. J. Mammal. 59: $354-365$.

Hafner J. C. and Hafner M. S. 1983. Evolutionary relationships of heteromyid rodents. Great Basin Natur. Mem. 7: 3-29.

Inger R. F. and Colwell R. K. 1977. Organization of contiguous communities of amphibians and reptiles in Thailand. Ecol. Monogr. 47: 229-253.

Jeffers J. 1981. [An introduction to system analysis: with ecological applications.] Mir, Moskva: 1-256. [In Russian]

Karr J. R. and James F. C. 1975. Ecomorphological configuration and convergent evolution of communities. [In: Ecology and evolution of communities. M. L. Cody and J. M. Diamond, eds]. Belknap Press., Massachusetts, Cambridge: $258-291$.

Kashkarov D. N. 1938. [Fundamentals of animals ecology.] Medgiz, Moskva-Leningrad: 1-601. [In Russian]

Lack D. 1947. Darwin's finches. Cambridge Univ. Press., Cambridge: 1-204.

Lemen C. A. and Freeman P. W. 1983. Quantification of competition among coexisting heteromyids in the Southwest. Southwest. Natur. 28: 41-46.

Lemen C. A. and Freeman P. W. 1987. Competition for food and space in a heteromyid community in the Great Basin desert. Great Basin Natur. 47: 1-6.

Lindsay E. N. 1972. Small mammals fossils from the Barstow Formation. California, Univ. California Publ., Geol. Sci. 93: 1- 104.

Mares M. A. 1976. Convergent evolution of desert rodents: multivariate analysis and zoogeographic aplications. Paleobiology 2: $39-63$.

Mares M. A. 1980. Convergent evolution among desert rodents: A global perspective. Bull. Carneg. Mus. Nat. Hist. 16: 1-51.

Martin P. S. and Mehringer P. J. 1965. Pleistocene pollen analysis and biogeography of the Southwest. [In: The Quaternary of the United States. H. E. Wright and D. G. Frey, eds]. Princeton Univ. Press., Princeton: $433-457$.

Munger J. C. and Brown J. H. 1981. Competition in desert rodents: an experiment with semipermeable exclosures. Science 211: $510-512$.

Patton J. L., Sherwood S. W. and Yang S. Y. 1981. Biochemical systematics of chaetodipine pocket mice, genus Perognathus. J. Mammal. 62: 477-492.

Petrov M. P. 1973. [World deserts.] Nauka, Leningrad: 1-434. [In Russian]

Plokhinsky N. A. 1970. [Biometry.] MGU, Moskva: 1-367. [In Russian]

Puzachenko Yu. G. and Skulkin V. S. 1980. [Vegetation structure in the forest zone of the USSR.] Nauka, Moskva: 1-273. [In Russian]

Puzachenko Yu. G., Skulkin V. S. and Rogovin K. A. 1990. [The analysis of the space structure of multispecies animal communities.] [In: General Problems of Biogeocenology. I. A. Shilov, ed.] Nauka, Moskva: 55-100. [In Russian]

Ricklefs R. E. and Travis J. 1980. A morphological approach to the study of avian community organization. Auk 97: $321-338$.

Ricklefs R. E., Cochran D. and Pianka E. R. 1981. A morphological analysis of the structure of communities of lizards in desert habitats. Ecology 62: 1474-1483. 
Rogovin K. A., Surov A. V. and Serrano V. 1985. Niche convergence in the desert rodents of two geographically isolated communities. Acta Zool. Mexicana (nueve serie) 10: 1-36.

Rogovin K. A. and Skulkin V. S. 1986. [Methodology of the analysis of multispecies mammal communities.] [In: General problems of biogeocenology]. The Transactions 2nd National Conference, 11-13 November, 1986, Moscow. Puschino: $161-163$. [In Russian]

Rogovin K. A., Shenbrot G. I. and Surov A. V. 1991. Analysis of spatial organization of a desert rodent community in Bolson de Mapimi (Mexico). J. Mammal. 72: 347-359.

Schoener T. W. 1974. Resource partitioning in ecological communities. Science 185: 27-39.

Shevyreva N. S. 1983. [Rodents (Rodentia, Mammalia) of the Neogene of Euroasia and northern Africa - evolutional basis of the Pleistocene and modern fauna of Palearctic rodents.] [In: Problems of theriology. History and evolution of modern fauna of rodents. I. Gromov, ed.]. Nauka, Moskva: 9-146. [In Russian]

Sinitzin V. M. 1967. [Introduction into Paleoclimatology.] Nedra, Leningrad: 1-232. [In Russian]

Skulkin V. C. 1978. [The use of iterative procedure for classification of vegetation.] Botan. Zh. 63 : 1123-1128. [In Russian]

Van Devender T. R. 1977. Holocene woodlands in the southwestern deserts. Science 198: 189-192.

Van Devender T. R. and Spaulding W. G. 1979. Development of vegetation and climate in the southwestern United States. Science 204: $701-710$.

Van Devender T. R. and Burgess T. L. 1985. Late pleistocene woodlands in the Bolson de Mapimi: a refugium for the Chihuahuan desert biota. Quaternary research 24: 1-8.

Wood A. E. 1935. Evolution and relationships of the heteromyid rodents with new forms from the Tertiary of western North America. Ann. Carnegie Mus. 24: 76-262.

Received 19 February 1990, accepted 9 November 1990. 